Cross-linguistic influence in third Language (L3) and fourth Language (L4) acquisition of the syntactic licensing of subject pronouns and object verb property: A case study

Tavakol, Mahboobeh

Department of English language, Yazd Science \& Research Branch, Islamic Azad University, Yazd, Iran (Mahboobehtavakol@yahoo.com)

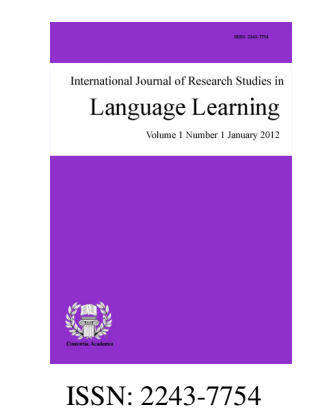

Jabbari, Aliakbar $\bowtie$

Department of English language, Yazd Science \& Research Branch, Islamic Azad University, Yazd, Iran (jabbari@yazduni.ac.ir)

OPEN ACCESS

\title{
Abstract
}

This study reports the results obtained through a stride to explore the type and extent of syntactic transfer in the early stages of adult L3 and L4 acquisition. Null-subject parameter (NSP) is a well-known and highly studied syntactic feature in generative studies on third language (L3) acquisition. Following a principles and parameters framework, the underlying principle of language is that languages have pronouns and the parametric variation is that Persian and Italian allow the pronouns to be dropped when in subject position. OV property of embedded clauses has also set itself as the basis of some formal studies on the realm of learning multiple languages. Whereas, the former set the languages with values of [+null-subject] and [-null-subject], the latter creates the language pairings as OV and non-OV languages. The syntactic licensing of null L3 and overt L4 pronominal subjects in declarative main clauses and the OV property in relative clauses were investigated to provide us with new insights on the true architecture of incipient multilingualism and, as such, to clarify the situation of a polyglot. The present instrumental case study was set to challenge the role of transfer during the acquisition of syntax in the initial state of adult L3 and L4. To quantify the cases of correct/incorrect suppliance of the features under investigation, the spontaneous, audio-recorded, productions of a Persian (L1)-speaking learner of L3 Italian and L4 German with advance L2 English proficiency were analyzed using obligatory occasion analysis and target like use analysis formulas. Based on the accuracy percentages generated via the formulas, the L2 status factor was consistently identified to play a significant role in the acquisition of L3 Italian and L4 German initial grammar.

Keywords: Third language acquisition; Fourth language acquisition; CLI; Transfer; L2 status factor; cumulative enhancement model 


\section{Cross-linguistic influence in third Language (L3) and fourth Language (L4) acquisition of the syntactic licensing of subject pronouns and object verb property: A case study}

\section{Introduction}

The question of how to account for the use and interpretation of overt versus null Subject Pronouns (SP) as a functional syntactic feature in [+pro-drop] and [-pro-drop] languages such as Italian and English respectively, has been addressed within various fields of linguistics, including theoretical syntax, sociolinguistics, and discourse pragmatics. It is a complex problem, given the fact that grammatical, semantic, pragmatic, cognitive, and socio-dialectal/contact factors can influence speakers' choice of null versus overt SPs. In the present study the issue of syntactic licensing of null versus overt subject pronouns is approached from the vantage point of cross-linguistic influence (CLI) in the acquisition of subsequent second languages, L3 and L4. Research in second language acquisition has made endeavors to identify various syntactic properties of the null-subject parameter and to determine which of these specific properties can be acquired by adult learners. On the other hand, OV property of subordinate clauses according to which the finite verb is in a final position is an intriguing syntactic feature which to the researchers' knowledge is less addressed at least with respect to the much-investigated field of L3 acquisition.

A major variable considered to be investigated throughout the study is syntactic transfer during multilingual acquisition. Considering the fact that the L3er has more than one possible source of transfer at disposal, Rothman, Iverson, and Judy (2011) posed four logical possibilities for how transfer manifests . The first position called 'no transfer position', suggests that all adult L3 acquirers experience the same language learning situation regardless of their language profiles. The second position which is referred to as the 'L1 factor' gives a significant role to the L1 as the only source of morphosyntactic transfer to all adult additive language acquisition. A third logical position is formalized as 'L2 Status Factor' maintains that the L2 has an outstanding role for morphosyntactic transfer. And consequently, a fourth position rejects the notion of privileged status for either of the previously acquired systems. Notwithstanding these four proposals, the generative L3 studies have provided conclusive evidence in favor of transfer from the previously acquired languages to the target language. However, there is still controversy over the major source of transfer. Given that the foci of the present study deal with the source and extent of syntactic transfer from the previously acquired languages to the target languages (L3 and L4), it is pertinent to briefly introduce the four main L3 morphosyntax models of transfer articulated in the generative L3 literature.

Embracing a generative point of view, the researchers in the field have taken three opposing and seemingly incompatible positions with respect to the role of morphosyntactic transfer from the previously acquired languages in the acquisition of L3/s. The first group of researchers advocate a straightforward position with respect to CLI as the properties of L1 fully determine the initial state of all adult second language acquisition (Schwartz \& Sprouse, 1994; Schwartz \& Sprouse, 1996) which is, in Rothman's (2013, p. 4) words, "full L1 transfer" and following the mainstream literature is referred to as Full Transfer/ Full Access (FT/FA). This model; however, is mainly concerned with adult second language rather than third language acquisition. With respect to L3/Ln acquisition (Hermas, 2014) has suggested that L1 is selected to be holistically transferred to the initial state of L3/s. if so, it could be argued that transfer is both facilitative and non-facilitative, and crucially based on the L1 and in fact, the results of Hermas' (2010) study of adult Arabic-French bilinguals revealed that the initial state of L3 is influenced exclusively by the final state of L1. This model of morphosyntactic transfer has come to be known under the label "the L1 factor hypothesis" which is not the focus of the present study. A second position mainly known under the label "L2 Status Factor Hypothesis" (LSFH) advocates the position that the properties of L2 will be transferred to L1 while blocking the positive transferable effects of L1 as a source of transfer to fully condition the initial state of L3/Ln acquisition which in turn, suggests the possibility of 
non-facilitative transfer (e.g. Bardel \& Falk, 2007; Falk \& Bardel, 2011; Bardel \& Falk, 2012b).

Bardel and Falk (in press) have further investigated the issue based on declarative vs. procedural knowledge distinction as offered by Paradis (2009). In this connection, L2 is elected for transfer because it is declarative as opposed to L1 which is mainly procedural (acquired); hence, more easily accessible. The third position, in essence, discards any sense of absoluteness regarding CLI, that is, it propagates the juxtaposing idea of transfer from both L1 and L2 to the target language. This position was divided into two different models of morphosyntactic transfer in incipient multilingualism in the main stream literature, namely, The Cumulative Enhancement Model (CEM) as proposed by Flynn, Foley, and Vinnitskaya (2004) and Typological Primacy Model (TPM) as stemmed from the study by Rothman and Cabrelli Amaro (2010) and later proposed under the label TPM by Rothman (2011).

The CEM claims that previous linguistic knowledge transfers in multilingual development from any language available to the multilingual learner irrespective of order of acquisition. However, transfer crucially only obtains when such knowledge has a facilitative effect, hence the expectation that redundancy in acquisition will not be observed (Rothman, 2013). According to Rothman (2013), still, there has not been much published work that provides conclusive evidence in line with or against the CEM. TPM, on the other hand, while reconciles the idea of L1 and/or L2 transfer, rejects the idea of non-redundant process of multilingual acquisition. The possibility of non-facilitative transfer, however, derives from the same general spirit underlying the original CEM, which is the belief that L3 developmental patterns, starting with transfer at the initial stages, reflect general cognitive economy reflexes that force language acquisition to be a non-redundant process. Both the CEM and the TPM agree that multilingualism is conditioned by a cumulative effect of previous linguistic acquisition; however, the TPM considers selection of a language for transfer as being conditioned by factors related to structural similarity between the languages at play, as opposed to mere facilitation.

From a generative perspective, null-subject parameter set the language with a \pm value as [+null-subject] or [-null-subject]. Therefore, we have two desired language pairings including: Italian (target language) and Persian (Source language) as [+null-subject] and German (TL) and English (SL) as [-null-subject]. In terms of the OV property the languages are divided to OV (L1 Persian and L4German) and non-OV (L2 English and L3 Italian). The instantiations of these two parameters have the potential to generate several contexts to test the aforementioned multilingual acquisition proposals, but, it should be notified here that the attention of the present study is directed towards LSFH and CEM.

\subsection{Predictions and hypotheses}

Transfer is either positive or it remains neutral, that is, transfer is only facilitative in the initial states of L3 and L4.

Transfer is holistic (both facilitative and non-facilitative), and crucially based on the L2, that is, there is an L2 status factor for the acquisition of L3 and L4 initial grammar

\section{Syntactic background}

\subsection{Null-Subject Parameter (NSP)}

Embracing generative views, Null Subject Parameter is generally known as a parametric variation found in the syntax of different (adult) natural languages. As a matter of fact, NSP, the binary values of which explain the syntactic licensing of pronominal subjects in natural languages, is a well-known and highly-studied parameter of grammar (Rothman \& Cabrelli Amaro, 2010). Most L2 and L3 studies on null-subject parameter share the assumption that there are two UG conditions on the null subject pro: licensing and identification (Rizzi, 1986). Licensing involves an appropriate licensing head, which governs the subject position via specifier-head 
agreement. Whether a language has a licensing head for pro, is a parameterized property: Agreement (Agr) is assumed to be a licensing head in [+ null subject] languages like Italian, but not in [- null subject] languages like English.

Generally speaking, based on word-order criterion, all natural languages are either configurational or pro-drop. In configurational languages such as English and German (set as L2 and L4 in this study, respectively) there is a fairly rigid word order based on a specifically ordered D-structure and likewise, all subjects must be overtly expressed (putting aside the entirely different imperative construction which can be subjectless). In null-subject or pro-drop languages such as Persian and Italian (set as L1 and L3 in this study, respectively) finite verbs i.e. verbs which carry tense, can have either an overt subject or a null pro subject. In other words, the latter group has the syntactic possibility of overt and null pronominal subjects. That is to say, Persian and Italian verbal inflectional affixes are considered to share the identical status of English and German overt pronominal subjects.
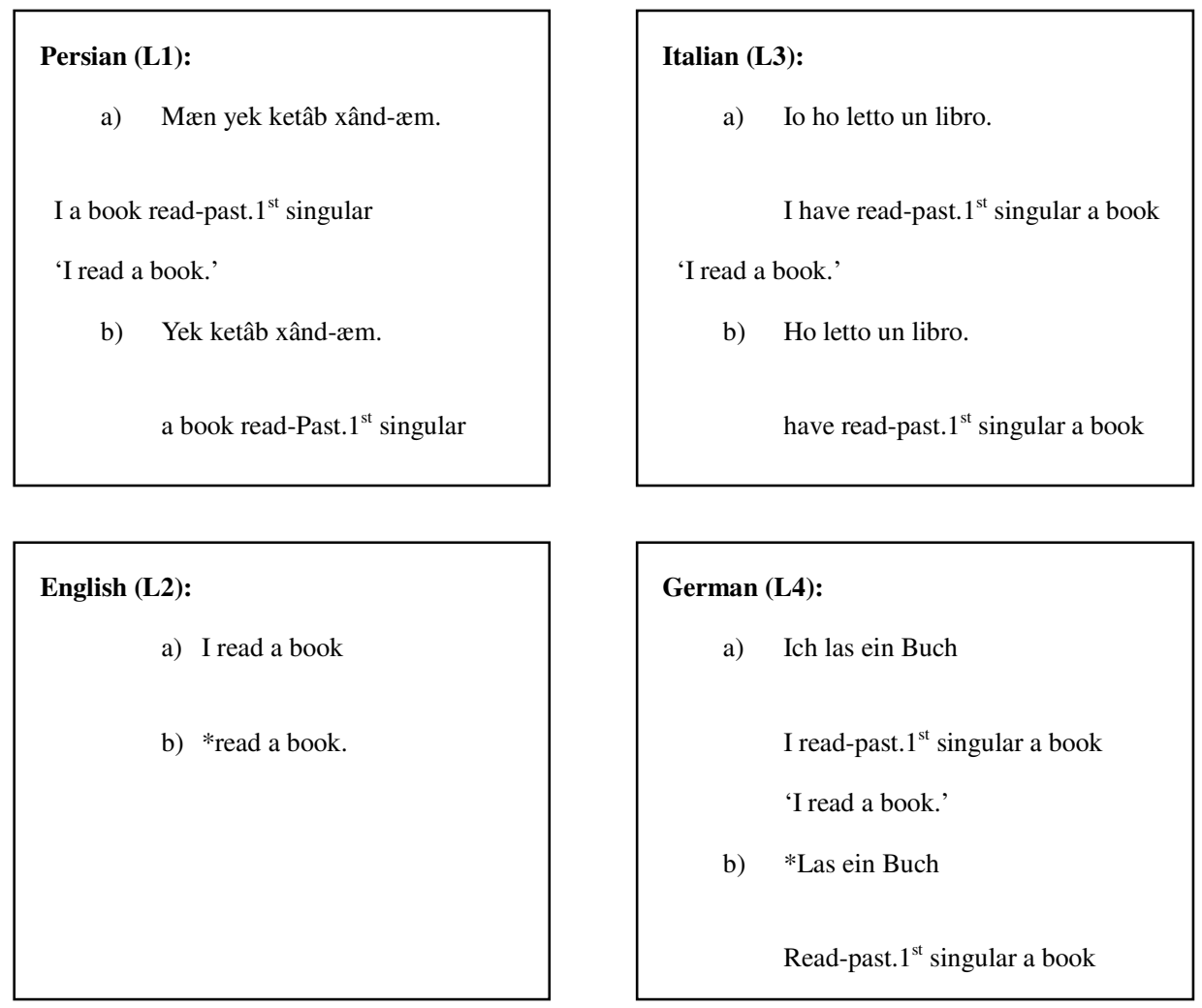

It is clear from the above examples that Persian and Italian are both [+null subject] languages with SOV and SVO word order, respectively. Their verbal morphology, as it was mentioned earlier, encodes interpretable phi-features. Most of the $\mathrm{L} 2 / \mathrm{L}_{\mathrm{N}}$ acquisition research studies concerned with null subjects share the assumption that cross-linguistic differences in the possibility of null subjects follow from a UG-sanctioned Null Subject Parameter (Sauter, 2002). This parameter gives us the following language pairings with respect to L3 and L4:

$$
L 3=L 1 \neq L 2
$$

$$
L 4=L 2 \neq L 1, L 3
$$

\subsection{OV property}

Generally speaking, the two basic syntactic properties of Object Verb (OV) and Verb second (V2) have consequences for the positioning of other constituents of the clause. In a subordinate clause, the finite verb is in a final position, thus it does not move out from its base-generated position, the OV property; and in a declarative 
main clause the verb is in a second position. Therefore, it could be argued that related to V2 parameter of the main clauses is the so-called OV property of subordinate clauses according to which the finite verb is in a final position, thus it does not move out from its base position. This is an intriguing feature of embedded clauses and above all relative clauses. Apart from free relative clause (which is not related to the present study), The formal distinction between restrictive, or integrated, relative clauses and non-restrictive, or supplementary, relative clauses in English is marked by prosody in speaking and punctuation in formal writing: a non-restrictive relative clause is typically preceded by a pause in speech or a comma in writing, whereas a restrictive clause normally is not. A critical feature of relative clauses of either types i.e. restrictive vs. non-restrictive, in natural languages is the relative position of finite verb and its complement which is syntactically referred to as object-verb property.

RCs in Persian and German - One of the most conspicuous features of German is the word order asymmetry between main and subordinate clause, with respect to the placement of the finite verb, as illustrated in (1) and (2).

1) Ich weiß, dass er es isst

I know, that he it eats

'I know that he eats it.'

In the relative clause in (1), the finite verb is in a final position, thus it does not move out from its base position (OV property); but in the main clause (2) the verb is in a second position (the V2 property). If we assume that the basic word order in German is SOV; there is an asymmetry in the word order. In the main clause, the V2 property forces the verb to be in the second position, giving rise to subject-verb inversion if the clause is introduced by another constituent than the verb. It must be noted that the two basic properties of German (OV and V2) have consequences for the positioning of other constituents of the clause.

Assuming the basic word order in Persian, where the object (internal argument) immediately precedes the verb and indirect objects also precede the verb being represented by prepositional phrases (PP), Persian does show the same OV property in relative clauses of either type; however, considering the fact that Persian is a non-V2 language the structure of the VP is consistently symmetric, that is, it always has the same basic structure, whether in a subordinate or a main clause ${ }^{1}$. The underlying structure in German and Persian VP is thus the following:

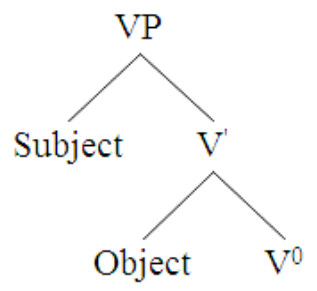

Figure 1. The German and Persian VP structure

The verb is generated to the right of the object and the subject is generated as the specifier of the V-bar, which is projected from the verb. In other words, in both Persian and German we assume that the verb is base-generated to the right, a position in which it stays in restrictive and non-restrictive relative clauses. The following examples clarify the OV property in both languages.

\footnotetext{
${ }^{1}$-Based on the universal basic structure the basic word-order is SVO in all languages while the asymmetry hypotheses supposes that a main clause only projects to IP whereas a subordinate clause projects to CP (eg. Czepluch, 1990)
} 


\section{Persian (L1):}

(RRC) Bærâdær-e mæn, ke shætranj bâzi mi-kon-æd, moælem æst.

Brother-Ez my, COMP chess play-present. $3^{\text {rd }}$ singular teacher COP

'My brother, who plays chess, is a teacher.'

(NRRC) Mærd-i ke engelisi dærs mi-dah-æd pedær-e mæn æst.

Man-IND COMP English teach- present. $3^{\text {rd }}$ singular father-Ez I COP

'The man who teaches English is my father.'

\section{German (L4):}

(RRC) Mein Bruder, der Schach spielt, ist ein Lehrer.

My brother, COMP chess plays, COP a teacher

'My brother, who plays chess, is a teacher.'

(NRRC) Der Mann ${ }^{\#}$, der Englisch unterrichtet ist mein Vater ${ }^{1}$

The man COMP English teaches COP my father

'The man who teaches English is my father.'

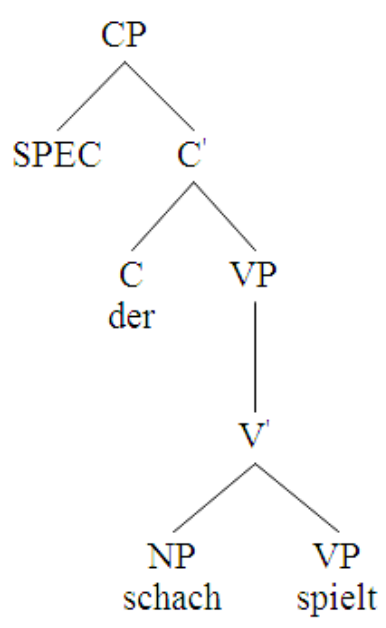

Figure 2. German relative clause's structure

RCs in English and Italian - English and Italian do not share the basic V2 and OV properties with German. The verb does not rise to a higher position than I in order to pick up its inflection. In English and Italian relative clauses, the finite verb occupies second position before the complement and after the subject pronoun. Further the same word order is found whether the clause is a main or a subordinate clause.

Italian (L3):
(RRC) Mio fratello, che gioca a scacchi, è un insegnante.
My brother, COMP plays chess, COP a teacher
'My brother, who plays chess, is a teacher.'
(NRRC) L'uomo che insegna inglese è mio padre.
'The man who teaches English is my father.'

\section{English (L2):}

(RRC) My brother, who plays chess, is a teacher.

(NRRC) the man who teaches English is my father.

With respect to generating the appropriate the language pairing of this thesis German and Persian are considered to possesses the OV property based on which the verbs are in a final position in relative clauses of either types, while English and Italian do not share this property and the verb is generated to the left of the object complement in the initial position. In terms of this property we could have the following pairings:

$L 3=L 2 \neq L 1$

$L 4=L 1 \neq L 2, L 3$ 


\section{The study}

\subsection{The subject}

Data used in this study are compiled from a female adult learner. She was more precisely, a Persian native speaker with three interlanguages: L2 English, L3 Italian and L4 German. She had a high command of L2 English in the early stages of L3 Italian and L4 German acquisition. It should also be noted that she was living in Yazd province, Iran at the time of data collection. Her spontaneous and semi-spontaneous productions of relative clauses (RCs) with respect to the OV property and declarative main clauses regarding the non/suppliance of subject pronouns were audio-recorded to be analyzed in terms of the possible errors she committed and also what she had right as possible result of positive transfer. The subject was not exposed to L3 and L4 prior to the start of data collection. She was home tutored by a proficient non-native speaker of Italian and German twice a week during a total of 12 month (6 month for Italian and 6 month for German). This way, it could be argued that it was a case of sequential as opposed to simultaneous multilingualism.

\subsection{Instrumentation and data collection}

The major instrument opted for the purpose of data collection was record examination and natural observation. This way the subject's L3 Italian and L4 German's spontaneous and semi-spontaneous productions were recorded at the initial states of acquisition while she was being privately tutored by the same Italian and German instructor. She was tutored during a total 44 sessions that is, 21 Italian and 23 German sessions. After the transcription and examination of the obtained corpora, the researchers decided to investigate the subjects' productions related to null-subject parameter (declarative main clauses) and OV property (relative clauses) which provided desirable language pairings in terms of the research aim of the present study. By desirable language pairings we mean $\mathrm{L} 4=\mathrm{L} 2 \neq \mathrm{L} 3, \mathrm{~L} 1$ in the case of NSP and $\mathrm{L} 4=\mathrm{L} 1 \neq \mathrm{L} 3, \mathrm{~L} 2$ in the case of OV property. To be clear then, the instantiations of these two parameters provided the researchers with tangible scenarios to test the abovementioned hypotheses regarding the morphosyntactic transfer in the initial state of adult multilingual acquisition. Collecting the instances of the structures' productions, the researchers not only generated the accuracy levels with which the structures were produced but they also, conducted an error analysis and inspected the learners' instances of incorrect suppliance of the structures to find the possible source(s) of material transfer.

\subsection{Scoring procedure}

In quantifying the cases of syntactic transfer from the previously acquired languages to the target languages that is, L3 and L4, the instances of correct versus incorrect use of the constructions under investigation were counted by the researchers in order to generate a level of production accuracy via target-like use analysis and obligatory occasion analysis formulas. The former was employed in terms of OV property and the latter was used in the case of null subject pronoun. By the mid-1970s, EA began to give way to another prominent method for identifying and describing developmental patterns, namely, Obligatory Occasion Analysis (OOA afterwards). This approach to the analysis of the learner's interlanguage data is clearly positioned by Brown (1973) and has been widely used by L2 acquisition researchers. The principal procedures in OOA, based on which one can observe the learner's learning trajectory, is as follows. First, samples of learner's spontaneous productions are collected. Second, obligatory occasions for the use of specific TL features are identified in the data (the audio-recorded data in this study). Thus, if in the course of learning an additional language the learners try to produce a linguistic feature, the obligatory occasion for the use of that specific target feature is created, although they may not always supply the features in question. Third, the percentage of accurate use of the feature is then calculated by establishing whether the feature in question has been supplied in all the obligatory contexts in which it is required. In the present study, the subject's accuracy in using the linguistic features was calculated by means of the following OOA formula: 


\section{(n) number of correct suppliance in contexts}

$(x)$ total number of obligatory contexts $\times 100=\%$ percentage of accuracy

In order to provide an operational definition of whether a linguistic feature has been acquired, a criterion level of accuracy must be determined. To take account of the fact that even adult native speakers may not achieve compete accuracy, the level is usually set at 80 to 90 percent, below 100 percent. Brown (1973) has considered a feature to be acquired if it was performed at the 90 percent level on three consecutive data collection points which is considered as a rigorous definition. Rif'ah and Sulistyo (2004), in their qualitative study on the accuracy of adult learners in using the past regular and irregular forms, set the level at 77 percent. In order to carry out the study's statistical procedure, the level of accuracy of use the learner was expected to achieve to forcefully claim that a feature is acquired is set at 80 percent. Therefore, in order to operationalize and to give a clear picture of the acquisition, if the learner achieves an accuracy score of 80 percent or higher, the feature is accounted as being 'acquired', but if the score is lower, it is considered as 'not acquired'. The choice of 80 percent as the minimum level for acquisition is made based on the fact that the learner was at the onset of L3 and L4 acquisition, and since the study does not investigate the developmental process in consecutive points, there was a one-shot like analysis of the obtained data. Figure 3 clearly illustrates the process of conducting an OOA.

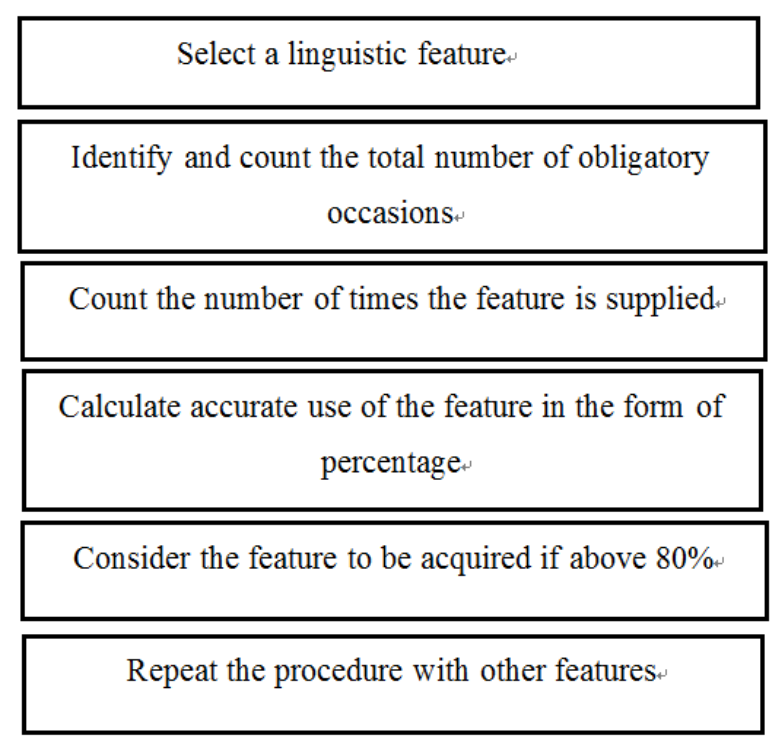

Figure 3. Hierarchy of conducting OOA, adopted from Ellis and Barkhuizen 2005 (p. 80)

Here, it is pertinent to mention that OOA suffers from a major shortcoming. It takes no account of when a learner uses a feature in a non-obligatory context in the TL. Consider for instance the case of subject pronoun which is obligatory in English but optional in Italian. If in producing Italian utterances the learner supplies the optional pronouns as if they are obligatory, it can be stated that the learner has over used this functional feature or has used it where the TL does not require it. It could be further argued that acquisition of a feature requires mastering not only when to use it but also when not to use it. To take account of overuses, a number of researchers have suggested a procedure known as target-like use analysis (e.g. Pica, 1983 cited by Ellis, 1994). Therefore, in order to take account of over suppliance of subject pronouns in Italian (which the above procedure fails to do), the researcher has employed the so-called target-like use analysis with the following formula:

(n) number of correct suppliance in contexts

$\overline{(x) \text { number of obligatory }+(y) \text { number of suppliance in }} \times 100=\%$ percentage of accuracy contexts non obligatory contexts 


\section{Results and discussion}

\subsection{Null-subject pronoun}

Analyzed utterances in Italian corpus - Interrogative and declarative main clauses with minimum length of one word (e.g. a conjugated verb)

$>$ Obligatory Contexts 1 (OC1): need an overt subject pronoun

$>$ Obligatory Contexts 2 (OC2): no need of an overt subject pronoun (there is no pronoun to be supplied)

$>\quad$ Optional contexts (OP): no need of an overt subject pronoun

Target-Like Use (TLU): suppliance of subject pronouns in OC1, non-suppliance of subject pronoun in OC2 and non-suppliance of subject pronoun in OP

Non-Target-Like Use (NTLU): non-suppliance of subject pronouns in OC1, suppliance of subject pronouns in OC2 and OP

Note: In addition to the instances of mere imitations or repetitions by the subject, the instances of wrong choice of subject pronouns in terms of gender and number of the corresponding verbs are counted as TLU since the focus is on non/suppliance.

Analyzed utterances in German corpus - Interrogative and declarative main clauses with minimum length of one word (e.g. a conjugated verb)

$>$ Obligatory contexts: need a subject pronoun in the PF

TLU: suppliance of the subject pronoun in all the obligations

NTLU: non-supliance of the subject pronoun in the obligatory contexts

Note: In addition to the instances of mere imitations or repetitions by the subject, the instances of wrong choice of subject pronouns that is we instead of you, are discounted.

\section{Table1}

Subject pronoun (functional feature), syntactic licensing of pronominal subjects, data collection A (Italian-corpus) \& B (German corpus)

\begin{tabular}{cccccccc}
\hline $\begin{array}{c}\text { Data } \\
\text { collection }\end{array}$ & Feature & $\begin{array}{c}\text { Obligatory } \\
\text { contexts }\end{array}$ & $\begin{array}{c}\text { Optional } \\
\text { contexts }\end{array}$ & $\begin{array}{c}\text { TLU in } \\
\text { contexts }^{\text {a }}\end{array}$ & $\begin{array}{c}\text { NTLU in } \\
\text { contexts }^{\mathrm{b}}\end{array}$ & $\begin{array}{c}\text { Suppliance in } \\
\text { OP contexts }\end{array}$ & $\begin{array}{c}\text { Accuracy } \\
\%\end{array}$ \\
\hline Italian & NSP & 14 & 61 & 19 & 56 & 53 & 28.35 \\
German & NSP & 59 & - & 51 & 8 & - & 86.44 \\
\hline
\end{tabular}

Note: the accuracy level for this non-obligatory feature is generated based on target-like-use analysis formula

a: obligatory + non-obligatory contexts

b: obligatory + non-obligatory contexts

Albeit, the absence of a part of speech in spontaneous oral production data can be hardly taken as an argument against transfer, the presence of an optional or null category that has been treated as an obligatory, overt structure could be forcefully taken as a sign of transfer. With respect to the fact that unlike L2 (English) which is [-null-subject] L1 and L3 are both [+null-subject], it could be forcefully inculcated that the learner is indeed supposed not to supply the subject pronouns in declarative main clauses in her Italian productions. It is noteworthy that NSP is a prominent feature investigation of which could shed searing light on multiple realities in adult non-native language acquisition. In light of the rudimentary record examinations, it was decided that the use of subject pronoun should be characterized based on both obligatory and non-obligatory or optional contexts 
in the initial state of L3acquisition. In a few cases it was obligatory not to supply the subject pronoun like in asking or expressing the time (Che ora é? ${ }^{*}$ what time is?, é l'una $=*$ is one o'clock) or asking and telling the price of something (Quanto costa? $*$ *How much costs?, costa ventinove dollari $=*$ costs 29 dollars), yet in most contexts created in the course of instruction it was optional either to supply or not. Also, there were a few contexts at the initial state of acquisition that the suppliance of subject pronoun is obligatory such as in the following example:
Example 1:
Io e il mio amico vanno a scuola ogni mattina.
I and my the friend go to school morning
'My friend and I go to school every morning.'

But the number these obligatory contexts did not exceed 3, so to avoid confusion they are not mentioned; but, they were counted as the obligatory contexts in order not to affect the results. The key issue was that the target-like use of the language would be culminated only when the feature is not supplied in optional contexts, therefore we have considered the subjects' performance as target-like if the pronouns are not supplied in either optional or obligatory. Already lurking in this argument, is the fact that obligatory occasion analysis disheartened us in the case of this special feature, thus a separate formula is applied in quantifying the cases of transfer and generating an accuracy percentage. In light of this, both obligatory and optional of are taken into account only in the case of L3 productions. Analogous to the cases of morpheme overuse, the target-like use formula could be applied and the non/target-like use are both taken into consideration in quantifying the number of times the learner has used the feature correctly.

Using this formula, the use and non-use of the subject pronoun in obligatory and optional contexts is counted to generate the accuracy percentage and those recordings are considered in which more instances of the use or non-use of the feature under investigation are found. German is, on the other hand is a non-null subject language and the target-like performance presumes the subject to supply the subject pronouns in declarative main clauses. But this establishes a noticeable confusion which could be simply avoided by using the same formula while considering zero optional contexts for the production of subject pronoun in L4 productions, and consequently the target-like performance is that of the learners' appropriate suppliance of all the subject pronouns.

Applying target-like use formula, there are no moot points about quantifying the cases of subject pronoun use. As it was bandied about formerly, in obligatory contexts the learner should not supply the subject pronoun such as when she is expressing the time or the price of something. There are a total of 14 obligatory contexts and 61 optional contexts. By target-like use the researcher means whenever the learner has not supplied the pronouns in neither of obligatory or optional contexts. But she has performed non-target liked when supplied the pronoun in both obligatory and optional contexts. The results convincingly show the accuracy percentage of 28.35 and based on the accuracy level predicted for this study it is forcefully indicated that the feature is not accurately acquired in L3 Italian. In other words while the learner has acquired the subject pronouns she has not acquired their function. An evaluation of the subject's errors forcefully suggest that there is a desire to suppress L1 as being non-foreign while it is the most economical source of transfer and to rely rather on an orientation towards L2 (English) in which the subject pronoun is obligatory. This clearly rejects the first prediction of the present study and likewise the third one since if L1 cannot play a viable role in the acquisition of an L3 feature even when it is the most economical source, a principal tenet of CEM regarding reflexive transfer will be violated.

In the case of L4 subject pronouns the data are coded in a way that target-like use is evidence of correct tokens while non-target like use refers to the instances of inappropriate or non-supliance of the feature. By the way, the number of optional contexts equals zero. As evident from the table, the feature is acquired with high accuracy percentage. Those utterances in which the subject has not supplied the subject pronoun in declarative main clauses yield the instances of non-target-like use. In the following excerpts from German corpus the learner 
has committed an error with respect to the omission of subject pronoun.

Example 2:

Instructor: in Ordnung, eh, sind sie glücklich?

All right, eh, are they happy?

The subject: Ja, sind glücklich.

yes, mmm, *are happy.

Instructor: warum?

Why?

(DCB, Rec \# 5, 6 September '12)

There is a great discrepancy between the languages with respect to this feature. As opposed to Italian (L3) +null subject parameter which is scarcely acquired as a result of incorrect transfer from - null subject English (L2), the accuracy percentage of 86.44 reported based on the learner's successful suppliance of subject pronoun in 51 out of 59 obligations, tout court, give the impression that L2 can take on stronger role than L1 as supplier and the main source in syntactic positive/negative transfer. This could corroborate our prediction regarding LSFH in L4 acquisition.

\subsection{OV property in RCs}

Analyzed utterances in Italian corpus - Embedded clauses containing at least a relative pronoun functioning as a subject, a finite verb and a complement

$>$ Restrictive relative clauses with 'verb + complement' structure

$>\quad$ Non-restrictive relative clauses with 'verb + complement' structure

TLU: non/restrictive relative clauses with finite verb followed by a complement

NTLU: non/restrictive relative clauses with finite verb preceded by a complement

Note: since the focus of the study was on the correct word order in the embedded clause, other types of errors e.g. wrong relative pronoun or incorrect form of the verb were ignored.

Analyzed utterances in German corpus - Embedded clauses containing at least a relative pronoun functioning as a subject, a finite verb and a complement

$>\quad$ Restrictive relative clauses with 'complement + verb' structure (OV property)

$>\quad$ Non-restrictive relative clauses with 'complement + verb' structure (OV property)

TLU: non/restrictive relative clauses with finite verb preceded by a complement

NTLU: non/restrictive relative clauses with finite verb followed by a complement

Note: since the focus of the study was on the correct word order in the embedded clause, other types of errors e.g. wrong relative pronoun or incorrect form of the verb were ignored.

\section{The corresponding scenarios:}

OV property in Italian: Scenario\#2, L3=L2, LSFH in L3 acquisition

OV property in German: Scenario\#4, L4=L1, FT/FA in L4 acquisition 
Tavakol, M., \& Jabbari, A.

Table 2

OV property (lexical feature), syntactic placement of finite verb in RCs with respect to their complements, DCA $\& D C B$

\begin{tabular}{|c|c|c|c|c|c|c|}
\hline Data Collection & Feature & $\operatorname{Record}(s)$ & Total & $\begin{array}{c}\text { Target-like } \\
\text { use }\end{array}$ & $\begin{array}{c}\text { Non-target like } \\
\text { use }\end{array}$ & Accuracy \% \\
\hline Italian & $\begin{array}{l}\text { OV Property in } \\
\text { RCs }\end{array}$ & $\begin{array}{c}13,14,16, \\
19\end{array}$ & 23 & 19 & 4 & 82.60 \\
\hline German & $\begin{array}{l}\text { OV Property in } \\
\text { RCs }\end{array}$ & $14,17,19$ & 19 & 11 & 8 & 57.89 \\
\hline
\end{tabular}

It could be generally assumed that since the learner was at the initial state of L3 and L4 acquisition, we found a restricted number of relative clause productions in record examinations and there was also a slight difference in the number of tokens across the languages. In quantifying the instance of non/restrictive relative clauses with respect to the so-called OV property, those productions were taken into account which are consistent with the normal function of relative clauses and involves having learners identify an object or person from others (Mackey \& Gass, 2005). To put it simply, all the tokens of restrictive or non-restrictive relative clauses containing a relative pronoun, verb and complement, were counted which assumed to yield an accuracy percentage for the acquisition of OV property in both Italian and German.

Here, it is pertinent to stress the difference in the accuracy level with which the learner produced the structure in L3 Italian and L4 German. This feature like NSP yields interesting language pairings, that is, L3=L2 and L4=L1. A comparison of the accuracy levels and an investigation of the errors committed by the learner again reveal how L2 guides or say, affects the acquisition of syntactic structures at the initial state of L3 and L4 acquisition. The language pairings generated based on this feature and the results of the analyses, tout court, confirmed the effects on the role of transfer of L2 status factor as a viable source of transfer. In a nutshell, the results of data analysis and the created accuracy levels consistently corroborated our prediction regarding the role of L2 in the acquisition of L3 Italian and L4 German of NSP and OV property at the early stages. However, the results clearly disconfirmed the possible effects of FT/FA as it is seemingly blocked by L2 as an overriding source of transfer and they violate, at least partly, the principal tenet at the heart of CEM which is reflexive transfer since there were frequent instances of non-facilitative transfer in the productions.

\section{Conclusions}

To date, studies are scarcely conducted to test the articulated models of L3 acquisition for various contexts and to the researchers' knowledge these models are not tested in the initial state of L4 acquisition to see if they can properly account for all the languages acquired after a true second language. Here it should be clarified that a true L2, based on the chronology of acquisition, is acquired after the mother tongue. As mentioned previously, the present study was an attempt to test the articulated models for the initial stages of adult third language (L3) morphosyntactic transfer and a preliminary stride to pinpoint the possible differences between the early stages of L3 and L4 acquisition.

In the present study set forth the possibility of non-facilitative transfer in L3 interlanguage based on the 'L2 status factor'. It was also discussed that the extent of and direction of transfer are nearly the same in the initial stages of L3 and L4 acquisition that is. No fundamental or drastic change was observed. However, it should be kept in mind that various variables interact in perplexing ways sometimes even converge to result in the incorporation of elements from a source language during L3 and L4 production, therefore, more systematic research is required. Notwithstanding the design of the present study let the researcher test the tenets of CEM and LSFH, it is important to mention that this study does not provide conclusive evidence but only an indication of how L2 influences the L3 syntax when the learner is in the initial state of L3/Ln acquisition and has access to limited L3/s input. Therefore, studies should be conducted (possibly with more than one case) to fully investigate the articulated models in adult L4 acquisition. It is very unlikely that the results apply to all language acquisition 
contexts, but with data at hand in tandem with evidence cumulated from several other studies on this much-debated issue of transfer during multilingual acquisition, it could be contended that transfer (positive versus negative) actually occurs.

To be clear then, multilinguals are not compartmentalized and mixing and merging of languages is inevitable during additive language acquisition. This implies that the linguistic properties of previously acquired languages could be used or sometimes highlighted to act as resources (but not sources) in instructed multilingual acquisition rather than being kept away or being considered as dysfunctional. The results obtained from such studies could add to the literature in that they test the articulated models and provide further evidence in varying context such as a foreign context in the present study where none of the L2s are spoken outside the classroom context. To put it in other words, the obtained results could provide a guideline as for the architecture of multilingualism and for the role play by the previously acquired languages in additive language acquisition. It should be also notified that an important direction for future research lies in the exploring of the true nature of multilingual acquisition through both spoken and written channels and intersection of implicit versus explicit knowledge while acquiring an additive language.

\section{References:}

Angelovska, T., \& Hahn, A. (2012). Written L3 (English): Transfer phenomena of L2 (German) lexical and syntactic properties Cross-linguistic Influences in Multilingual Language Acquisition (pp. 23-40): Springer. http://dx.doi.org/10.1007/978-3-642-29557-7_2

Bardel, C. (2010). The lexicon of advanced L2 learners. High-level proficiency in second language use. Berlin: Mouton de Gruyter.

Bardel, C., \& Falk, Y. (2004). Can processability be transferred. Paper presented at the Fourth International Symposium on Processability, Second Language Acquisition and Bilingualism. University of Sassari.

Bardel, C., \& Falk, Y. (2007). The role of the second language in third language acquisition: the case of Germanic syntax. Second Language Research, 23(4), 459-484. http://dx.doi.org/10.1177/0267658307080557

Bardel, C., \& Falk, Y. (2012a). Procedural distinction. Third language acquisition in adulthood, 46, 61.

Bardel, C., \& Falk, Y. (2012b). What's behind the L2 factor? A neurolinguistic framework for L3 research. Third Language Acquisition in Adulthood. Amsterdam: John Benjamins (in press).

Brown, R. (1973). A first language: The early stages: Harvard U. Press. http://dx.doi.org/10.4159/harvard.9780674732469

Ellis, R. (1994). The study of second language acquisition: Oxford University Press, USA.

Ellis, R., \& Barkhuizen, G. P. (2005). Analysing learner language: Oxford University Press, USA.

Falk, Y., \& Bardel, C. (2011). Object pronouns in German L3 syntax: Evidence for the L2 status factor. Second Language Research, 27(1), 59-82. http://dx.doi.org/10.1177/0267658310386647

Flynn, S., Foley, C., \& Vinnitskaya, I. (2004). The Cumulative-Enhancement Model for Language Acquisition: Comparing Adults' and Children's Patterns of Development in First, Second and Third Language Acquisition of Relative Clauses. International Journal of Multilingualism, 1(1), 3-16. http://dx.doi.org/10.1080/14790710408668175

Hermas, A. (2010). Language acquisition as computational resetting: verb movement in L3 initial state. International Journal of Multilingualism, 7(4), 343-362. http://dx.doi.org/10.1080/14790718.2010.487941

Hermas, A. (2014). Multilingual transfer: L1 morphosyntax in L3 English. International Journal of Language Studies, 8(2), 10-24.

Mackey, A., \& Gass, S. M. (2005). Second language research: Methodology and design: Routledge.

Paradis, M. (2009). Declarative and procedural determinants of second languages (Vol. 40): John Benjamins Publishing. http://dx.doi.org/10.1075/sibil.40

Pica, T. (1983). Adult acquisition of English as a second language under different conditions of exposure. 
Tavakol, M., \& Jabbari, A.

Language learning, 33(4), 465-497. http://dx.doi.org/10.1111/j.1467-1770.1983.tb00945.x

Rif'ah, F. N., \& Sulistyo, G. H. (2004). An obligatory occasion analysis of the use of past regular and past irregular forms in recount texts of VIII graders of SMP1 bogonegoro.

Rizzi, L. (1986). Null objects in Italian and the theory of pro. Linguistic inquiry, 17(3), 501-557.

Rothman, J. (2013). Linguistic and cognitive motivations for the Typological Primacy Model (TPM) of third language (L3) transfer: Timing of acquisition and proficiency considered. Bilingualism: Language and Cognition, 17(2), 1-12. http://dx.doi.org/10.1017/S136672891300059X

Rothman, J., \& Cabrelli Amaro, J. (2010). What variables condition syntactic transfer? A look at the L3 initial state. Second Language Research, 26(2), 189-218. http://dx.doi.org/10.1177/0267658309349410

Rothman, J., Iverson, M., \& Judy, T. (2011). Introduction: Some notes on the generative study of L3 acquisition. Second Language Research, 27(1), 5-19. http://dx.doi.org/10.1177/0267658310386443

Sauter, K. (2002). Transfer and access to universal grammar in adult second language acquisition. GRODIL, Secretary Department of General Linguistics.

Schwartz, B. D., \& Sprouse, R. (1994). Word order and nominative case in nonnative language acquisition: a longitudinal study of (L1 Turkish) German interlanguage. Language acquisition studies in generative grammar, 31(4), 71-89.

Schwartz, B. D., \& Sprouse, R. A. (1996). L2 cognitive states and the Full Transfer/Full Access model. Second Language Research, 12(1), 40-72. http://dx.doi.org/10.1177/026765839601200103 